\title{
From Hershel's discovery to the thermal camera calibration
}

\author{
Waldemar Minkina, Robert Bąbka \\ Institute of Electronics and Control Systems, Częstochowa University of \\ Technology \\ Al. Armii Krajowej 17, 42-200 Częstochowa, Poland \\ minkina@el.pcz.czest.pl, rbka@el.pcz.czest.pl
}

\section{Oral presentation}

Keywords: Planck's law, thermal camera calibration, camera spectral range, camera sensitivity.

\section{Introduction}

In 1800 Sir Frederick William Herschel discovered an existence of the invisible radiation which is able to carry an energy [1,2]. Moving a thermometer (radiation sensor) along the visible sunlight spectrum, he noticed temperature grow also next to red part of the spectrum. He called this infra-red as invisible heat. 100 years after that, Max Planck analysing data from measurements showed mathematical relation between temperature of the ideal black body, wavelength of radiation and power density of the black body radiation. Nowadays the Planck's low is the basis for remote temperature measurement by means of the infrared radiation $[3,4,5,6]$.

The Planck's formula allows clearly explain what Hershel discovered as well as how the thermal camera calibration process is conducted. Authors propose original explanation both of them using computer animation prepared in Matlab.

\section{Hershel's experiment presentation}

At the present time the Planck's law has been proven definitely. So using his formula we can simulate how sir Hershel has obtained his temperature curve along the observed spectrum.

The received radiation caused temperature grow at the thermometer placed in wavelength range $\left(\lambda_{1}, \lambda_{2}\right)$ can be calculated using equation [5]:

$$
E\left(T, \lambda_{1}, \lambda_{2}\right)=\int_{\lambda_{1}}^{\lambda_{2}} \frac{S(\lambda) C_{1}}{\lambda^{5}\left[\exp \left(\frac{C_{2}}{\lambda T}\right)-1\right]} d \lambda
$$

where: $C_{1}=3,74 \cdot 10^{-16} \mathrm{~W} \cdot \mathrm{m}^{2}, C_{2}=1,44 \cdot 10^{-2} \mathrm{~m} \cdot \mathrm{K}, S(\lambda)$ - resultant sensitivity of the experimental system. 
On the basis of (1) a computer animation has been made (Fig. 1). It shows a course of the experiment and obtained results.

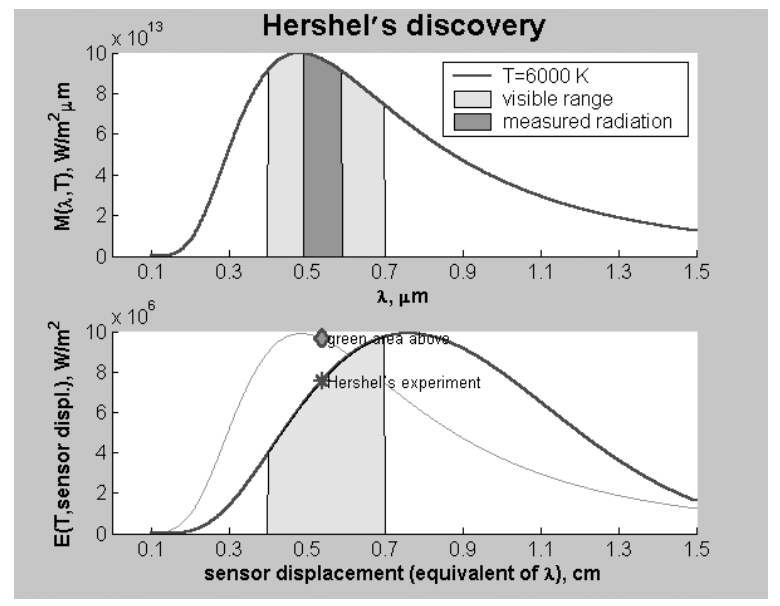

Fig. 1. An explanation of the Hershel's experiment (animation) The factor $S(\lambda)$ causes that Hershel's curve (red) is different form integral of the Planck's equation (green doted curve).

\section{Thermal camera calibration process}

A calibration process of the thermal camera in similar way has been explained. The animations were prepared to show how the calibration curve is obtained. These below (Fig. 2) present course of the calibration process for short-wave and long-wave thermal cameras.

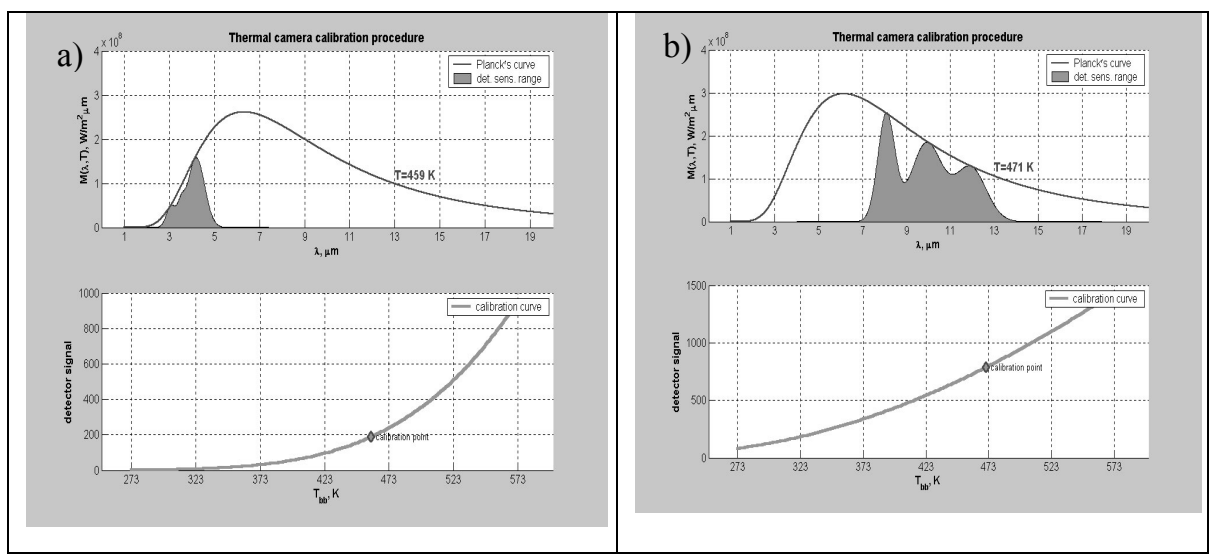

Fig. 2. Thermal camera calibration procedure

a) short-wave (SWB) thermal camera

b) long-wave (LWB) thermal camera 


\section{References}

[1] Herschel W.: Experiments on the refrangibility of the invisible rays of the sun. Philosophical Transactions of the Royal Society of London, Vol. 90, pp. 284-293, 1800.

[2] Herschel J.F.W. (Junior): Preliminary discourse on the study of natural philosophy. Printed for Longman Rees. Grme, Brown. \& Green: Paternoster Row and John Taylor upper Gower Street, London, 1830.

[3] Chrzanowski K.: Non-Contact Thermometry, Measurements Errors. SPIE PL, Research and Development Treatises, Vol. 7, Warsaw 2000.

[4] FLIR: Research \& Development (R\&D) Level II -2000, Infrared Training Center - International (itc-i).

[5] Minkina W., Rutkowski P., Wild W.: Thermovision Measurement Basics. Pomiary, Automatyka, Kontrola (PAK) 46 (2000) Nr 1, part I - pp. 7-10 and part II, pp. 11-14 (in polish).

[6] Minkina W.: Thermovision Measurement Basics. Pomiary Automatyka Kontrola (PAK) 47 (2001) Nr 11, part III, pp. 5-8 (in polish). 